\title{
O TESTEMUNHO DA CARNE: UM PEQUENO TRATADO SOBRE A ALEGORIA EM UMA obra de Diamela Eltit
}

\section{The testimony of the flesh: a small treatise on allegory into a work by Diamela Eltit}

\author{
Emerson Pereti* \\ Marilene Weinhardt*
}

\begin{abstract}
RESUMO
Em Impuesto a la carne, a escritora chilena Diamela Eltit expõe um quadro alegórico da nação chilena em seu bicentenário, representado por meio da relação simbiótica entre mãe e filha, personagens que compartilham, por duzentos anos, uma existência precária no micromundo de um hospital. Tendo por base teórica os apontamentos de Walter Benjamin sobre a alegoria e os estudos das alegorizações fundacionais e pós-ditatoriais de Doris Sommer e Idelber Avelar, propõe-se aqui uma leitura parcial da obra, levantando algumas questões sobre seu operativo alegórico, principalmente no que se refere às relações conflitivas entre sujeito e nação, história e testemunho, poder e resistência.
\end{abstract}

Palavras-chave: Impuesto a la carne; Diamela Eltit; alegoria; resistência.

\footnotetext{
ABSTRACT

In Impuesto a la carne, the Chilean writer Diamela Eltit deals with an allegoric view of the Chilean Nation on its bicentennial.

* Doutorando em Estudos Literários UFPR.

** Professora Doutora UFPR/CNPq.
} 
This is represented by the symbiotic relationship between a mother and a daughter. These characters share, for two hundred years, a precarious existence in the micro-world of a hospital. Taking into account the theoretical researches about allegory by Walter Benjamin and the studies on foundational and post-dictatorial allegorizations by Doris Sommer and Idelber Avelar, a partial reflection on this is given. This research emphasizes on some issues about the allegoric operability of the novel, mainly on the conflictive relationship between subject and nation, history and testimony, power and resistance.

Keywords: Impuesto a la carne; Diamela Eltit; allegory; resistance.

Como narrar a partir da derrota? Como construir, por meio das palavras, a resistência àquilo que foi, àquilo que a violenta história se encarregou de consumar? Como, animal que se arrasta no tempo, virar para trás e reconhecer o que lhe quebrou a espinha dorsal ${ }^{1}$ Como, fugindo da catástrofe, voltarmo-nos para dar adeus à cidade, sem que esse movimento não nos converta em estátua de sal? Nessa tentativa de arrastar o desejo ao regresso da perda se instala a alegoria, no espaço intransponível entre o anjo da história e as ruínas, no tempo arrastado por causa da resistência das asas. Movida talvez por essa imperiosa e ao mesmo tempo inexecutável vontade, uma parte da produção literária contemporânea nos países do Cone-Sul americano, justamente aquela voltada ao trabalho do luto pós-ditatorial, tem dado à alegoria um espaço de significativa importância. ${ }^{2}$ Nessa literatura que emerge como extensão do trauma ditatorial, no entanto, o alegórico não mais atua como a relação convencional entre uma imagem ilustrativa e um sentido abstrato - característica da arte feita sob censura - mas como imagem arrancada de uma totalidade definitivamente destruída pelas ditaduras, que se volta reincidentemente sobre a perda na tentativa de entendê-la.

Sob essa perspectiva, a alegoria, ao incidir sobre a derrota, tentando extrair dela sempre um significado, ainda que transitório, opera dialeticamente. A intenção neste estudo é empregar essa relação, aparentemente paradoxal, entre alegoria e dialética, proposta ainda nos anos 20 por Walter

${ }^{1}$ Mas está fraturado o teu dorso / meu estupendo e pobre século. / Com um sorriso insensato / como uma fera um tempo graciosa / tu te voltas para trás, fraca e cruel / para contemplar as tuas pegadas." Os versos finais do poema "O século", de Osip Mand'stam, citado por AGAMBEN, Giorgio. O que é contemporâneo? e outros ensaios. Tradução de Vinícius Nicastro Honesko. Chapecó: Argos, 2009. p. 62.

${ }^{2}$ Entre as narrativas pós-ditatoriais publicadas a partir dos anos 2000, destacamos aqui algumas que podem ser lidas a partir de seu operativo alegórico. Entre elas: Mano de obra e Impuesto a la carne, de Diamela Eltit; Nocturno de Chile, de Roberto Bolaño; Dos veces junio, de Martín Kohan, e Apenas diez, de Mariza Silva Schultze. 
Benjamin, ${ }^{3}$ para fazer uma leitura da obra Impuesto a la Carne, publicada em 2010 pela escritora chilena Diamela Eltit. Provavelmente um estudo a partir de outras linhas teóricas, como a biopolítica, por exemplo, possa ser bastante produtivo no que se refere a este texto, não obstante, procuraremos nos ater especificamente à sua expressão alegórica como força dialética que problematiza e põe em "pausa reflexiva", principalmente no espaço de luto pós-ditatorial, a conflituosa relação histórica entre sujeito e nação, história e testemunho, poder e resistência.

\section{Alegoria e dialética}

Em seu famoso ensaio sobre a Alegoria, em Origem do drama trágico alemão, de 1928, Walter Benjamin estabelece uma polêmica com os críticos românticos que preferiam o conhecimento resplandecente do símbolo à impossibilidade da linguagem expressa pela alegoria. Para Benjamin, essa escolha, de certa forma assumida em toda a cultura ocidental pós-romântica, não se resumiria meramente a uma questão de juízo estético, porém, mais profundamente, a uma apreciação do valor do tempo e da história. Os românticos, ao optarem pelo imediatismo individual e pretensamente transcendental do símbolo, haviam estabelecido uma apoteose quase divina do indivíduo. A apoteose barroca, a sua vez, propõe Benjamin, seria dialética, porque seu assunto não podia se restringir apenas ao individual, mas tinha de incluir uma dimensão político-religiosa e, portanto, coletiva. Se o símbolo havia sido empregado pelos românticos como uma forma de fundir significante e significado por meio da "iluminação" particular e espontânea do poeta, para Benjamin, a alegoria (allo, outro, agorein, dizer) extrairia sua vida justamente do abismo intransponível entre os dois. Porém, nessa impossibilidade de fundir signo e referente residiria justamente sua capacidade dialética; ela não tenta fazer desaparecer a falta de uma verdade definitiva para o conhecimento humano, mas se aprofunda ao cavar essa falta, ao tirar daí imagens renovadas, pois nunca conclusas. Enquanto o símbolo aponta para a eternidade da beleza, a alegoria ressalta a impossibilidade de um sentido eterno e a necessidade de perseverar na temporalidade para constituir significações transitórias. A reabilitação da alegoria por Benjamin será, como lembra Jeanne-Marie Gagnebin, uma reabilitação da história, da

${ }^{3}$ Cf. BENJAMIN, Walter. Origem do drama trágico alemão / Walter Benjamin. Edição e tradução de João Barrento. Belo Horizonte: Autêntica Editora, 2011. 
temporalidade e da decadência humanas, expressa por meio da impossibilidade paradoxal da linguagem. ${ }^{4}$

Enquanto no símbolo, com a transfiguração da decadência, o rosto transfigurado da natureza se revela fugazmente na luz da redenção, na alegoria o observador tem diante de si a facies hippocratica da história como paisagem primordial petrificada. A história, com tudo aquilo que desde o início tem em si de extemporâneo, de sofrimento e de malogro, ganha expressão na imagem de um rosto - melhor, de uma caveira. E se é verdade que a esta falta toda a liberdade "simbólica" da expressão, toda a harmonia clássica, tudo o que é humano - apesar disso, nessa figura extrema da dependência da natureza exprime-se de forma significativa, e sob a forma do enigma, não apenas a natureza da existência humana em geral, mas também a historicidade biográfica do indivíduo. Está aqui o cerne da contemplação de tipo alegórico, da exposição barroca e mundana da história como via crucis do mundo: significativa, ela o é apenas nas estações da sua decadência. Quanto maior a significação, maior a sujeição à morte, porque é a morte que cava mais profundamente a tortuosa linha de demarcação entre a phýsis e a significação. ${ }^{5}$

Aqui reside talvez uma das grandes contribuições de Walter Benjamin para uma leitura da Modernidade em tempos ditos pós-modernos: 0 olhar do crítico para a história não pode ser feito apenas pela totalidade do símbolo, é preciso reconhecer também a face cadavérica dessa história, as ruínas, os fragmentos, as reminiscências de mundos abortados. Isso pode parecer demasiado pessimista, e de fato o é, porém, não exime a possibilidade utópica. O dom de despertar no passado as centelhas de esperança, lembrará mais tarde o próprio Benjamin em suas considerações sobre o conceito da história, é privilégio exclusivo do historiador convencido de que também os mortos não estarão em segurança se o inimigo vencer, mesmo que tenhamos a ciência de que aquilo que chamamos de história tem sido

${ }^{4}$ Cf. GAGNEBIN, Jeanne-Marie. História e narração em Walter Benjamin. São Paulo: Perspectiva, 2009. Particularmente o capítulo Alegoria, Morte, Modernidade. p. 31-53.

${ }^{5}$ BENJAMIN, Walter. Origem do drama trágico alemão. op . cit., p. 176-177. 
uma sucessão quase ininterrupta de derrotas. ${ }^{6}$ A verdade da interpretação alegórica consiste, por conseguinte, nesse movimento de fragmentação e de desestruturação da enganosa totalidade histórica. A crítica não pode preservar somente a beleza da aparência sensível, mas também ater-se às ruínas que tal aparência carrega; e uma vez atenta a esses destroços, deles fazer o objeto de sua meditação. Somente esses destroços, esses fragmentos dispersos de uma totalidade, reconhecida como sendo enganosa, deixam entrever outra realidade; disso a alegoria extrai seu caráter dialético, e, talvez, transformador. Esse trabalho nos indica assim que o sentido não nasce tanto da plenitude e da eternidade, como também, do luto e da história, mesmo se, por meio deles, estamos em busca de outro tempo. ${ }^{7}$

\subsection{Alegorias progressivas e regressivas no conteXto latino-Americano}

Tomamos aqui, rapidamente, dois exemplos do emprego desse caráter dialético "construtivo" da alegoria, proposto por Benjamin, em leituras contemporâneas sobre a Literatura Latino-americana; particularmente de dois temas que aproximam, como tentaremos mostrar mais tarde, o circuito alegórico de Impuesto a la carne. Uma delas trata da interpretação da alegoria enquanto elemento unificador entre amor erótico e ideia de pátria, apresentada por Doris Sommer em estudo sobre os romances nacionais na América Latina; a outra, da alegoria e o trabalho do luto na ficção pós-ditatorial latino-americana, presentes no livro Alegorias da derrota, de Idelber Avelar.

Em Ficções de fundação, Doris Sommer faz uso do conceito de alegoria benjaminiano para descrever, a partir dele, a relação interligada entre o erotismo e a política por meio da qual se funda o desejo pela pátria em romances latino-americanos do século XIX. A autora parte de pontos de convergência ${ }^{8}$ entre a História da sexualidade, de Foucault, e Comunidades Imaginadas, de Benedict Anderson, para propor que, nesses romances, as visões da Nação e do sexo, intercambiáveis, reforçam-se mutuamente, desalojando ligações anteriores e impelindo o discurso em direção ao futuro

${ }^{6}$ BENJAMIN, Walter. Sobre o conceito da história. In: Magia e técnica, arte e política: ensaios sobre literatura e história da cultura. Tradução de Sérgio Paulo Rouanet 7 . ed. São Paulo: Brasiliense, 1996. p. 224-225.

${ }^{7}$ GAGNEBIN, Jeanne Marie. História e narração em Walter Benjamin. Op. cit., p. 45.

${ }^{8}$ Sommer observa o cruzamento das linhas de pesquisa dos respectivos autores em dois lugares fundamentais. Um relaciona-se à questão da época escolhida: o final do século XVIII, quando se origina o discurso fundamental para cada caso (o sexo, para Foucault, e o patriotismo, para Anderson). O outro ponto de convergência é a denegação de ambos os autores: todo discurso marcadamente histórico afirma ser atemporal e essencial à condição humana. SOMMER, Doris. Ficções de fundação: os romances nacionais da América Latina. Tradução de Gláucia Renate Gonçalves e Eliana Lourenço de Lima Reis. Belo Horizonte: Editora UFMG, 2004. p. 51. 
"desejado" da pátria. Segundo Sommer, ao aceitar um certo tipo de traduzibilidade entre desejos românticos e republicanos, escritores e leitores do cânone de romances nacionais latino-americanos da época estavam pressupondo uma relação "alegórica" entre narrativas pessoais e políticas. Para uma leitura dessa afinidade, se faria necessária uma utilização menos convencional do conceito de alegoria, conceito este que a autora encontraria justamente em Benjamin:

[...] Tramas de amor e tramas políticas estão o tempo todo se sobrepondo. Em lugar do paralelismo metafórico entre, por exemplo, paixão e patriotismo, que os leitores provavelmente esperam da alegoria, vamos ver aqui uma associação metonímica entre amor romântico, que precisa das bênçãos do Estado, e legitimidade política, que precisa ser fundada no amor. Walter Benjamin oferece um caminho para se sair desse impasse terminológico através de sua combinação pouco ortodoxa entre a alegoria e a dialética, um caminho que contorna a noção bastante convencional de alegoria apresentada por Fredric Jameson, bem como a visão ácida de Paul de Man. ${ }^{9}$

Em direção oposta ao princípio dialético destacado pelo autor alemão, Sommer propõe que nessas ficções de fundação, a alegoria trabalha como uma força que coloca o desejo em um movimento espiral ou em ziguezague dentro de uma estrutura dupla, que está sempre em direção ao futuro, à medida que o erotismo e o patriotismo levam um ao outro, para seguirem assim adiante. $O$ que chama a atenção da autora nesse tipo de produção é que o poder de sua receptividade parece residir justamente no fato de que cada investimento libidinal cobre a aposta feita pelo outro, e cada obstáculo encontrado pelos amantes serve tanto para aumentar seu desejo mútuo de se tornar um casal como para aumentar seu amor (assim como o dos leitores) pela Nação possível, na qual esse caso de amor poderia enfim se consumar. ${ }^{10} \mathrm{~A}$ relação dialética entre amor e pátria por meio da alegoria seria, deste modo, não apenas o eixo fundamental dessas narrativas, mas também o "impulso libidinal" a uma certa parte da população, leitora obviamente, em sua procura pela consumação de um "novo país". Isso explicaria também o fato de que essas ficções formadoras tenham sido legitimadas e difundidas mais tarde pelos Estados Nacionais, que preparavam um governo autorizado, usando, como matéria-prima, inclusive o amor erótico.

${ }^{9}$ Ibidem, p. 59-60.

${ }^{10}$ Ibidem, p. 67. 
Essa leitura da alegoria enquanto força que impele um desejo futuro de formação da nação parece também "pouco ortodoxa" à ideia de Benjamin. Postergamos, entretanto, o debate, e tomamos a articulação alegórica progressiva, proposta por Sommer, para contrastá-la com a leitura "alegórica" a partir do impulso regressivo à ruína ditatorial, tratada por Idelber Avelar em Alegorias da derrota.

O estudo de Avelar traça uma topologia da derrota em alguns romances pós-ditatorias escritos no Brasil, Chile e Argentina, nos anos da chamada "redemocratização" desses países. Seu estudo parte do pressuposto de que as ditaduras, como instrumentos de transição epocal do Estado ao Mercado, representam uma ruptura na substituição compensatória, empregada pelo boom sessentista, do atraso social e político pelo "avanço" literário no subcontinente. Seu argumento é que essa operação compensatória do boom se esvazia no momento em que as ditaduras fazem da modernização o horizonte inelutável da América Latina.

\begin{abstract}
Enquanto que o boom havia tentado reconciliar a pulsão modernizadora com o restabelecimento compensatório do aurático no pós-aurático, tal reconciliação passa a ser completamente impossível, esvaziada a priori por uma tecnização que aniquila implacavelmente a aura do literário e desvela essa aura como resquício de um momento ainda incompleto do desdobramento do capital. ${ }^{11}$
\end{abstract}

Não ocasionalmente, segundo Avelar, a data do ocaso do boom, situada por volta de 1972 ou 1973, coincidiria emblematicamente com a queda do grande projeto social alternativo latino-americano naquele momento, a Unidade Popular de Salvador Allende. 11 de setembro de 1973, seria assim, a data alegórica para o desfecho do boom: "Depois do 11 de setembro já não nos seria dada a possibilidade, para dizê-lo lapidarmente, de acreditar no projeto de redenção pelas letras". ${ }^{12}$ Para Avelar, na literatura que emerge desse colapso, pelo menos aquela que elencou em seu estudo, o imperativo é o trabalho do luto e a decadência da arte de narrar. Ao contrário da alegoria como propulsora de um devir, como na leitura de Sommer dos romances fundacionais, alguns trabalhos de Ricardo Piglia, Silviano Santiago, João Gilberto Noll, Tununa Mercado e da própria Diamela Eltit são, em sua análise, expressões da passagem traumática do Estado ao Mercado, passagem esta que implica uma transformação radical da experiência. Esse tipo de

${ }^{11}$ AVELAR, Idelber. Alegorias da derrota: a ficção pós-ditatorial e o trabalho do luto na América Latina. Tradução de Saulo Gouveia. Belo Horizonte. Editora UFMG, 2003. p. 22.

${ }^{12}$ Ibidem, p. 23. 
literatura viria assim de um impulso em direção ao passado ditatorial, que se ergue como ruína. Esse tropo alegórico do impossível necessariamente responde a uma impossibilidade fundamental, uma quebra irrecuperável na representação, que sobrevive, porém, dialeticamente, por meio dela como alegoria. Deste modo, a própria percepção dessa irredutibilidade pode ser trazida ao espaço cívico, e instaurar, ao menos, sua pausa reflexiva. ${ }^{13}$

\section{Aleggorizações de uma históRia IMPosta À CARne}

Impuesto a la carne inscreve-se ainda nesse horizonte da derrota que caracteriza os romances pós-ditatoriais analisados por Avelar. Contudo, neste livro, o jogo alegórico do luto se projeta para além do espaço-tempo da ditadura nazipinochetvista, e arrasta-se, a contrapelo da história hegemônica, às origens discursivas da nação. Nesta narrativa híbrida (parece mais confortável chamá-la assim), Diamela Eltit expõe um quadro alegórico da nação chilena em seu bicentenário, ${ }^{14}$ representado por meio da relação simbiótica entre mãe e filha, personagens que compartilham, por duzentos anos, uma existência precária em um hospital. Assim como havia utilizado o supermercado como micromundo de seu romance, Mano de obra, de 2002, Eltit faz uso do hospital como micro-espaço alegórico da Nação, espaço este a partir do qual são impostas as formas de poder sobre os indivíduos. Essa intencionalidade de explorar os espaços marginais a partir do fragmento e o trabalho com restos experienciais já não representáveis como totalidades coerentes são características marcantes na obra de Eltit. Sua estética criativa faz parte de um complexo contexto de evolução da literatura e das artes no Chile: a crise definitiva da escrita militante, agora forçada a reconsiderar as premissas básicas de sua relação com a linguagem, e a emergência de uma ficção e uma poesia que tratam de repensar a experiência traumática do pós-golpe ${ }^{15} \mathrm{~A}$ proposta literária de Eltit se gesta a partir de sua participação na Ensena de Avanzada, grupo de artistas e intelectuais que haviam permanecido, e que procuravam intervir nos espaços da memória simbólica do Chile, frequentemente em uma espacialidade alternativa à dos recintos de arte cercados pela instituição. Em meio à censura institucionalizada, os artistas de Avanzada se veriam obrigados a encontrar estratégias de atua-

${ }^{13}$ Ibidem, p. 33.

${ }^{14}$ A data intencional para a publicação do livro, justamente no ano em que se comemoram, no Chile, os duzentos anos de independência, não deixa de ser, também ela, alegórica.

${ }^{15}$ AVELAR, Idelber. Alegorias da derrota. Op. cit., p. 191. 
ção e divulgação artística sempre pondo em questionamento as normas de representação e da relação entre arte, vida e política no Chile. Em todo seu leque de recursos estéticos de vanguarda, a Avanzada se tornaria assim uma referência chave para grande parte da literatura chilena pós-golpe. Nesse bojo de atividades artísticas, é importante destacar o papel das mulheres para a criação de espaços de reflexão sobre temas políticos contingentes como a sexualidade, o autoritarismo, o doméstico, as políticas do cotidiano e a identidade de gênero. Erna Pfeiffer, ao destacar a produção literária escrita por mulheres no Chile do pós-golpe destaca:

Por las condiciones específicas de la violencia política, la censura y la clandestinidad, las escritoras se ven desafiadas, al mismo tiempo, a ir en busca de nuevos procedimientos y nuevas estructuras artísticas. Es una constelación histórica, ya que por un lado tienen de usar complejas estrategias de cifrado, por razones extraliterarias; por otro lado, uno de sus objetivos centrales es precisamente la descentralización del sujeto hegemonial, logocéntrico. Así, coinciden dos vertientes que se van intensificando mutuamente, creando textos extraordinariamente opacos, marginales, resistentes a una lectura fácil, por no hablar de su "vendibilidad", su comercialización en el mercado burgués y neoliberal del libro. ${ }^{16}$

Aqui se insere o projeto de escritura de Diamela Eltit, uma proposta teórica, estética, social e política a partir de outros espaços de leitura. Impuesto a la carne é resultado ulterior, pós-ditatorial, dessa intersecção de experimentações cifradas em tempos de censura, e de descentralização do sujeito hegemonial logocêntrico por meio da escritura a que se refere Pfeiffer. Gestada a partir da intensificação mútua dessas duas constantes, a escritura de Eltit pode agora, em tempos pós-ditatoriais, se voltar a uma releitura crítica da construção narrativa da nacionalidade chilena.

\subsection{Alegorizações AnTIFUndacionais, o CORPo DEVASTADo Do QUE RESISTE}

Na América Latina, os movimentos independentistas não representaram a culminação de uma reforma iluminista do entendimento, nem um conceito igualitário e democrático de sociedade, nem a secularização da história. Não revogaram o Estado nacional católico, herdado das mo-

${ }^{16}$ PFEIFFER, Erna. Reflexiones sobre la literatura feminina chilena. In: KONUT, Karl. SARAVIA, José Morales (Eds.). Literatura chilena hoy: la difícil transición. Madrid: Iberoamericana; Frankfurt/Main: Vervuert, 2002. p. 70-71. 
narquias portuguesa e espanhola. Tampouco significaram uma mudança de mentalidades com respeito às formas católicas de vida baseadas nos princípios escolásticos de soberania e submissão. Não puseram fim ao racismo colonial e muito menos projetaram uma reforma na sociedade civil. ${ }^{17}$ O sujeito enunciador do discurso fundacional do Estado-nação na América Latina, durante o século XIX, tinha um projeto patriarcal e elitista que excluiu não só índios e negros escravos, mas também mulheres, analfabetos e, em muitos casos, quem não tinha propriedade. ${ }^{18}$ No Chile, assim com em outras nações latino-americanas, a construção discursiva da pátria se fez por meio de projetos crioulos solidamente arraigados à tradição feudal do colonialismo espanhol. Seu conceito de independência cerrava fileiras em torno de dois grandes instrumentos de dominação hispânica: a fé de Roma e a língua de Castilla. ${ }^{19}$ Para as comunidades indígenas, negras e mestiças dos países "libertados", a independência representou, antes de tudo, uma nova investida de violência e desapropriação, fundamentada agora nos preceitos liberais e individualistas, principalmente em assuntos sobre direito de terra e propriedade. Os discursos pátrios, constructos da cosmovisão das classes hegemônicas, se instauraram nesses países como projeto unificador sobre "outras nações" presentes no território dito nacional. Um discurso estendido como circuito histórico linear; uma autoridade discursiva que apagou, suprimiu ou canibalizou vastas práticas imaginativas de outros estratos populacionais. Os romances fundacionais do século XIX, estudados por Sommer, são também extensão desse projeto discursivo. Sua popularização e institucionalização por parte dos novos governos republicanos, a que se refere a autora, são também uma tentativa de propor uma linearidade histórica a partir de um ponto singular, para criar uma consciência de pertencimento em uma grande parte da população que, marginalizada no espaço político, se situou historicamente em permanente crise de identidade real-simbólica frente a um projeto de unidade nacional..$^{20}$

${ }^{17} \mathrm{Cf}$. SUBIRATS, Eduardo. "Antropofagia" contra globalización. In: . Una última visión del paraíso: ensayos sobre media, vanguardia y la destrucción de culturas en América Latina. México: Fondo de Cultura Económica, 2004. p. 102.

${ }^{18} \mathrm{Cf}$. ACHUGAR, Hugo. Planetas sem boca: escritos efêmeros sobre arte, cultura e literatura. Tradução de Lyslei Nascimento. Belo Horizonte: Editora UFMG, 2006. Particularmente o capítulo: "Ensaio sobre a nação no início de século XXI: breve introdução in situ/ab situ". p. 203.

${ }^{19}$ Cf. SUBIRATS, Eduardo. Una última visión del paraíso. Op. cit., p. 102.

${ }^{20}$ Não obstante, à parte dos argumentos de certas teorias pós-colonialistas que não distinguem as condições coloniais e pós-coloniais latino-americanas das demais no mundo colonizado, e também em refutação ao pensamento neoliberal de superação do Estado pelo Mercado, instaurado a partir das ditaduras recentes, é importante lembrar ainda que é "a partir" do "espaço nacional" que também se têm construído, ao longo da história pós-colonial latino-americana, as lutas pela afirmação étnica e identitária, além daquelas que se orientam pela soberania dos povos, pela justiça econômica e pelas políticas da memória. 
A modernidade latino-americana seguiu cultivando no século XX uma estrutura social que em muitos aspectos conservava os legados feudais: a reincidente divisão castista, os valores prelatícios de obediência e poder patriarcal, muitas vezes defendidos pela corrupção e crueldade de seus caciques e governantes, como os ditadores retratados nos romances de Miguel Ángel Asturias e Augusto Roa Bastos, testemunhos literários dessa modernidade autoritária, corrupta e retrógrada. A história pós-colonial latino-americana se estendeu assim como continuidade sem fissuras entre o universo simbólico e político colonial e as práticas de espólio, segregação racial, autoritarismo político até o final do século XX. As ditaduras nacionais, aqui mais especificamente as instauradas nos países do Cone-Sul, se inserem nesse continuum; agora, como lembra Idelber Avelar, como instrumentos de transição epocal do Estado nacional ou populista para o Estado-Mercado, preparando assim, nesses países, o terreno para a implantação da terceira fase do capital. ${ }^{21}$

Impuesto a la carne é uma recuperação alegórica dessa trágica história pós-colonial latino-americana, aqui resumida à experiência chilena. Ao longo do texto, são recorrentes as alegorizações de vários episódios da história do país. Essas imagens, em sua força poética enquanto alegoria, em sua sempre transitória e dialética expressividade, permitem uma leitura antifundacional da história a partir do fragmento, das reminiscências, dos lampejos de memória, das repetições insistentes e do próprio silêncio que suscitam. O título - uma referência aos trágicos protestos de 1905 que resultaram na morte de centenas de pessoas entre as que protestavam em frente a La Moneda contra o aumento da carne argentina ${ }^{22}$ - atua alegoricamente como traço entre a repressão histórica do Estado hegemônico sobre as comunidades marginalizadas e o poder hospitalar a que estão submetidos os corpos das protagonistas na narrativa.

Se o espaço do supermercado, tratado em Mano de obra, havia sido o local a partir do qual se descreve uma metáfora da fagocitação do sujeito

${ }^{21}$ AVELAR, Idelber. Alegorias da derrota. Op. cit., p. 263.

${ }^{22}$ Em 1905, o governo chileno, defendendo os interesses dos latifundiários locais, decretou a cobrança de taxas de importação sobre o gado argentino. A alta de preços gerou uma série de protestos que foram duramente reprimidos pelas forças do governo. Os cálculos das mortes variam dependendo da versão histórica, estima-se, contudo, que de 200 a 250 pessoas tenham morrido durante a repressão, entre centenas de feridos. A huelga de la carne, também conhecida como Semana roja, é um episódio emblemático na história chilena, por um lado porque expõe a situação degradante em que grande parte da população trabalhadora vivia, em contraste com as classes hegemônicas, por outro, a irrupção, dentro dos movimentos de trabalhadores, do pensamento político organizado, principalmente o anarquista. Cf. GRES TOSO, Sergio. Una mirada al movimiento popular desde dos asonadas callejeras (Santiago, 1888-1905). Revista de Estudios Históricos, v. 3, n. 1, ago. 2006. Disponível em: <http:// www.estudioshistoricos.uchile.cl/CDA/est_hist_complex/0,1475,SCID\%253D18809\%2526ISID\%253D 650\%2526PRT\%253D19160,00.html>. 
público na sociedade de consumo pós-ditatorial chilena, ${ }^{23}$ a alegoria do hospital serve a Eltit para juntar dois elementos chave em sua narrativa, a história e o corpo. Impuesto a la carne trabalha, no plano alegórico, no interstício entre esses dois espaços. A história, alegorizada como ambiente hospitalar, espaço de poder, sórdido, ruinoso, por onde circulam médicos soberbos e autoritários, enfermeiras corruptas, pacientes terminais e fãs avidamente preocupados com a "saúde pública" / e o corpo dessas mulheres, como espaço alegórico (e político) de resistência. Sob um regime de obsessiva enfermidade, vivem as protagonistas, desde seu traumático nascimento, condenadas a uma vida de males e doenças constantes; submetidas, em sua tentativa de sobrevivência, ao tratamento autoritário e soberbo do corpo médico.

Así le dijo a mi mamá: Bajas / feas / seriadas, se lo dijo en un orden en cierto modo musical, se lo dijo cuando ella sentía los peores dolores del mundo y el médico le diagnosticó o profetizó que por una serie de condiciones íbamos a contagiarnos de todo o a enfermarnos de todo o a morirnos de casi todo. El médico primero o el médico fundador (del territorio), como prefiere identificarlo de manera burocrática mi mamá, quiso que naciéramos (él tenía el poder o la gracia de permitir la vida y decidir la muerte). ${ }^{24}$

A escolha desse ambiente alegórico parece bastante sugestiva em um país no qual a classe médica tem um trânsito bastante fluente na política. ${ }^{25} \mathrm{E}$ ainda mais sugestiva se levarmos em conta as "metáforas médicas", das quais se utilizaram as ditaduras recentes no Cone-Sul americano, como cura à "doença subversiva". ${ }^{26}$ Os médicos no romance serão, consequentemente, expressões alegóricas de uma classe política responsável pela "saúde

${ }^{23}$ Cf. ELTIT, Diamela. Mano de obra. Santiago de Chile: Planeta, 2002.

${ }^{24}$ ELTIT, Diamela. Impuesto a la carne. Buenos Aires: Eterna Cadencia Editora, 2010. p. 25. Todas as referências da obra são desta edição.

${ }^{25}$ A classe médica é historicamente ativa no campo político chileno. Mesmo nas atuais campanhas políticas, é comum que candidatos advindos da classe médica apareçam em suas propagandas de campanha vestidos com a indumentária médica padrão (jaleco e estetoscópio), com seus nomes sempre antecedidos pelo axiônimo de "doutor". A ideia frequente, ao que parece, é associar a saúde da nação à saúde física de seu povo. Devemos estas informações aos alunos chilenos do Centro de Línguas e Interculturalidade da UFPR, sobretudo à aluna Constanza Egaña que, em sua leitura particular, nos ajudou também a elucidar outros fatos importantes da história chilena que perpassam o texto literário.

${ }^{26}$ Cf. Também NOVARO, Marcos; PALERMO, Vicente. A ditadura militar argentina 1976-1983: do golpe de estado à restauração democrática. Tradução de Alexandra de Mello e Silva. São Paulo: Editora da Universidade de São Paulo, 2007; e FREDRIGO, Fabiana de Souza. Ditadura e resistência no Chile: da democracia desejada à transição possível (1973-1989). Franca: UNESP, 1998b (Série Estudos, n. 03). 
pública" de uma "Nação", sujeita esta a todo o tipo de enfermidade social. ${ }^{27}$ De sua parte, mãe e filha tentam sobreviver a esse regime doentio apenas com a resistência de seus depauperados corpos. Se o hospital é el territorio, o la nación, o la pátria, se os médicos são seus governantes autoritários e soberbos, essas duas mulheres representam a força coletiva de uma subalternidade que resiste à aniquilação. Não por acaso essas protagonistas, os sujeitos enunciadores do discurso, são duas mulheres, mãe e filha, anciãs, baixas, morenas, feias, seriadas (e anarquistas): personas tan ancianas, económicas, parias, bajas, morenas, oblicuas, anarquistas como somos nosotras. Essas duas mulheres têm duzentos anos, posto que a mãe ancestral, na grande hemorragia que suporta para a criação da pátria, nasce novamente ao dar à luz a filha. A complexa, tensa, simbiótica relação entre mãe e filha, sua consciência de terem apenas uma a outra, ao longo desses icuántos? ¿doscientos años? intensifica o poder biopolítico dessa resistência, porque esse sujeito, ainda que impossibilitado pela irredutibilidade da linguagem, é plural, pertinentemente histórico e, a sua vez, coletivo.

Representamos una forma de expiación con la que prueban la fortaleza de sus vocaciones: la energía, disciplina y la férrea autoridad nacional que ejercen sobre nosotras. Tenemos la misión que acompaña a las sobrevivientes de unos icuántos?, no sé, ¿doscientos años? Nosotras debemos dar cuenta de la historia y detenernos en cada uno de los episodios turbios o en aquellos que portan una metafísica falsificada. Porque nos proponemos enfrentar un tiempo colmado de dados inciertos o definitivamente silenciados. Queremos resumir, repensar, repeler ciertas versiones impropias. Somos testigos de una cantidad tan significativa de años que podríamos oficiar como las más confiables historiadoras inorgánicas de nuestro extenso tiempo. ${ }^{28}$

\subsection{Do QUE SE REPETE E DO QUE SILENCIA}

Percebe-se, em Impuesto a la carne, aquela intempestividade descrita por Avelar, discordante da literatura de mercado, característica da impossibilidade de narrar, da crise aguda entre experiência e representação

${ }^{27}$ Como a referência aos "médicos generales": “[...] Se niega a aceptar mi madre que ellos no tenían escrúpulos porque practicamente no nos examinaban y nos trataban con una violencia que no comprendo cómo há podido disculpar", ou ao médico-ditador do qual não se dispõe aqui dizer o nome: "[...] no hay ningún especialista, solo um médico general, entusiasmado con su cargo pero asimétrico como todos los médicos generales. Um general. Incompetente. Sanguinario". ELTIT, Diamela. Impuesto a la carne. Op. cit., p. 55 e 91, respectivamente.

${ }^{28}$ Ibidem, p. 23. 
instaurada no presente pós-ditatorial. Diante dessa impossibilidade, o narrador, ao menos aquele capaz de perceber a escuridão de seu tempo ${ }^{29}$ olha para o passado em busca de resposta, esse narrador intempestivo permanecerá insistentemente com os olhos sobre o que foi, procurando ver, entre as ruínas, os vestígios de uma redenção futura, porque, ao vislumbrar a facies hippocratica da história, redescobre o próprio presente como "estado de exceção". ${ }^{30}$ A alegoria surge então como pausa reflexiva, imagem arrastada no tempo, abundante de significados, justamente por não comportar uma totalidade coerente, representação testemunhal de "una memoria que no se termine de comprender de todo y que, sin embargo, nos permita hacer um milímetro de historia". ${ }^{31}$

Essa impossibilidade de encontrar, por meio das palavras, uma forma de descrever o passado e o presente é, ainda que em seu paradoxismo, - e aqui voltamos a apelar à dialética da alegoria proposta por Benjamin - potencialmente transgressora enquanto narrativa. Transgressora porque comporta uma constelação de possibilidades históricas, que mesmo irredutíveis à representação, movimentam e deslocam o discurso hegemônico em sua transitoriedade. É transgressora inclusive nos silêncios que encerra, porque esses espaços vazios, inenarráveis, impõem uma pausa reflexiva, incômoda, que abre fissuras na linearidade discursiva, estimulam uma contra-marcha em direção ao passado e se amotinam, também eles, como forma de resistência. Nas constantes discussões entre mãe e filha, encontra-se sempre esta constante: narrar, insurgir-se contra a história, ou subsistir por meio do que silencia, para gerar seu grande manual histórico do tratado da postergação:

Pero mi madre se niega a corregir o aun a discutir la versión más manipulada o injusta o deliberada de la historia. Piensa que cualquier palabra nuestra va a desencadenar la furia médica [...] Los médicos, dice mi madre, no van a soportar que llevemos hasta el espacio público sus propias somatizaciones o que revisemos los métodos y las retorcidas teorías mediante las cuales han consolidado sus planes expansivos. No, no, dice mi madre, los médicos nunca podrían aceptar la dimensión sórdida que incrementa sus intereses, sus pugnas repetidas y carentes de matices, [...] Tendrías que ser tonta o retardada, me dice mi mamá, para profanar la burbuja histórica de la nación, del país o de la patria médica, así es que te repito, cállate la boca y déjalos en paz... ${ }^{32}$

\footnotetext{
${ }^{29} \mathrm{Cf}$. AGAMBEN, Giorgio. O que é contemporâneo. Op. cit.

${ }^{30} \mathrm{Cf}$. BENJAMIN, Walter. Sobre o conceito de história. Op. cit.

${ }^{31}$ ELTIT, Diamela. Impuesto a la carne. Op. cit., p. 31.

${ }^{32}$ Ibidem, p. 30.
} 
A recusa da mãe em insurgir-se contra a realidade hospitalar, e isso é perceptível ao longo da obra, não pode ser confundida com aceitação ou conformismo alienante diante das constantes opressões infligidas pelas juntas médicas, da vontade autoritária desse grupo de criar um estado de constante "enfermidade social", nem mesmo à constatação de que o sangue das duas é comercializado inescrupulosamente pelas enfermeiras. ${ }^{33}$ A opção pelo silêncio parece ser, antes de tudo, uma estratégia de sobrevivência. Como a própria filha reconhecerá mais tarde: "Mi madre es cuidadosa. Dotada de su lucidez anarquista puede ser considerada una verdadera estratega de la sobrevivencia". ${ }^{34} \mathrm{Em}$ uma sociedade patologicamente enfermiça, torna-se também patológica, para essas mulheres, a ideia de persistir, ainda que seja por meio da entrega desistida aos tratamentos cirúrgicos e medicamentosos, assim como às demais condições estabelecidas pelo regime hospitalar. Não há um horizonte de mudança, este é o único presente da Nação, o "estado de exceção" a que estamos acostumados e sem o qual (parece) não saberíamos viver, o estado de exceção em que é imperiosa apenas a sobrevivência.

Yo no comprendo cómo podría vivir sin mi mamá, como sería mi existencia sin médicos ni enfermeras, sin dar mi sangre siempre, sin estar sentada esperando que un médico me examine y después me asuste con darme muerte si no me pliego a sus órdenes y medicamentos. No sé vivir sin experimentar el castigo de la patria o de la nación o del país. Este país que no devuelve el mar, que no devuelve el mar... ${ }^{35}$

Essa entrega, dissimuladamente resignada, que se configura como única estratégia praticável de resistência, é a própria força que movimenta o discurso, sempre a partir da constatação paradoxal de que simplesmente não é possível narrar. Diante da impossibilidade da narradora de construir seu relato é que também irrompem no texto as constantes repetições. Como na sequência da passagem: "El castigo interminable de un territorio que me saca sangre, que me saca sangre, me saca sangre, me saca sangre. Que me

\footnotetext{
${ }^{33}$ Destacamos aqui, a nível de elucidação, esta passagem referente às práticas das enfermeiras: "Siento que me voy a desmayar porque la enfermera de turno ya me ha sacado demasiada sangre que va a vender a un precio razonable mezclada con la sangre de mi mamá, sí, de mi pobre madre tan enferma y anciana. Mi mamá que tiene que entregarle sangre gratuitamente a nuestro hospital patrio, a nuestro recinto nacional, a todo el territorio hospitalario del país para que mantengan viva las enfermeras que sirven a los médicos con una dedicación no sé si voluptuosa pero sí insensata. Los sirven para que los medicamentos triunfen en el cuerpo de los pacientes." Ibidem, p. 70.

${ }^{34}$ Ibidem, p. 94.

${ }^{35}$ Ibidem, p. 31.
} 
saca sangre.". ${ }^{36}$ A repetição desesperada incide sobre o inexequível retorno, desacelera o tempo, inscreve-se como lembrança latejante no tempo, porque repetir é aferrar-se à memória como luta política contra os discursos de poder, contra o esquecimento passivo, as provas forçadas de que é impossível mudar esse estado de coisas. Mais do que isso ainda, reincidir sobre a denúncia é também parte importante do trabalho de luto, a vontade da testemunha de levar a perda a um futuro no qual se possa, talvez, entendê-la.

Assim como a repetição constante, os silêncios trabalham em Impuesto a la carne como estratégia de resistência. Há recorrentes vazios no texto que dizem mais, em sua impossibilidade expressiva, que a narração linearmente inteligível. Há coisas das quais não se pode falar, há um silêncio insondável sobre elas, uma vontade inexprimível que sobrevive como ruína de um discurso obliterado, algo que pulsa dentro da inexistência como a sensação tátil, em um corpo mutilado, de um membro perdido. Como o silêncio tabu em relação ao passado ditatorial:

No puedo soportarlo, no quiero ver a mi madre así, subyugada por esa enfermera, oprimida por el médico, pero me callo porque se digo una sola palabra me va a inyectar, lo sé, lo he visto en innumerables películas, lo presencié en la extensión de las calles $\mathrm{y}$ hemos experimentado en nuestro propio pellejo las terribles represiones, las torturas (cállate, cállate) y la costumbre histórica por adormecer y matar. ${ }^{37}$

Esse silêncio encerra a vontade de representação de um mundo interrompido e despedaçado não apenas pelo regime genocida do pinochevismo. O imperativo do cállate é a expiação histórica que acompanha, resistindo, a linearidade discursiva da Nação. Ele lembra da impossibilidade da linguagem de representar toda a injustiça disseminada sob a bandeira de uma ordem cívica. É uma expressão coletiva, histórica, a própria alegoria de tudo o que foi calado nesses ¿cuántos? ¿doscientos años? de construção discursiva do nacionalismo. Como aquele que acompanha o massacre da Escola Santa Maria de Iquique.

Esa unión, la mía y de mi madre, es una alianza indisoluble que nos ha mantenido vivas aunque no sanas por ¿cuánto? ¿doscientos años? Unos años muy difíciles, históricos, dañinos (cállate,

${ }^{36}$ Ibidem, p. 81.

${ }^{37}$ Ibidem, p. 73. 
no hables de las dificultades, no digas, no te atrevas a decir una sílaba de la insurrección del norte). ${ }^{38}$

O silêncio sobre essa insurreição do norte - a matança de trabalhadores, mulheres e crianças, metralhados indiscriminadamente pelas forças do governo chileno, disposto a fazer valer a vontade dos empresários ingleses ${ }^{39}$ - é um testemunho, a carga da incompreensão e da atonia perante a experiência traumática que carrega o trauma, perplexo, sem dizê-lo. Porque não há como entender o abismo instaurado por ele, exprimi-lo por meio da linguagem, resta apenas impor-lhe um silêncio carregado de interrogação. E o curioso é que esse silêncio, trazido à polis pela escritura literária, possa falar tanto, senão mais do humano que a historiografia documental, sempre preocupada com datas, números, governos e ciclos econômicos.

A impossibilidade de narrar o passado traumático ou o futuro redentor se impõe sobre o corpo devastado do presente, o corpo das protagonistas. Mas essa impossibilidade é justamente o que confere impulso e legitimidade a seu testemunho. Seu silêncio é a constatação aterradora do que foi, do que é, e do que poderia ser, o cállate de cada passagem corresponde à pausa dialética do que se conserva inatingível pelos recursos da língua. $\mathrm{O}$ trabalho do luto consiste também nesse silêncio reflexivo sobre o tabu, porque a violação desse interdito acarretaria, supostamente, o castigo divino, que poderia recair sobre o culpado ou seu grupo, e esse castigo é justamente o esquecimento passivo, a mãe parece saber disso. Não obstante, conservando seu impulso em direção ao passado, esse cállate de alguma forma interrompe o continuum da máquina discursiva da Nação, a coloca em pausa reflexiva, reincide sobre ela tentando extrair algum significado, alguma razão para as inumeráveis mortes. Nisso consiste sua dialética, porque, ao fazer isso, posterga um significado pleno e empurra a perda, paradoxalmente, em direção ao futuro, para que se construa algo melhor a partir dela. O silêncio em Impuesto a la carne instaura-se, assim, na pólis, no espaço hospitalar, também ele, como meio de testemunho, resistência e rebeldia. Seu esforço expressivo, assim como a imagem alegórica, está direcionado àqueles que

${ }^{38}$ Ibidem, p. 80.

${ }^{39}$ A matanza de la Escuela Santa María de Iquique aconteceu no dia 21 de dezembro de 1907. Nessa ocasião, foi assassinado um grande número de trabalhadores do salitre de diversas nacionalidades que se encontravam em greve geral, enquanto se alojavam na Escola Domingo Santa María do porto de Iquique. A greve, provocada pelas míseras condições de trabalho e exploração dos trabalhadores, foi reprimida por meio de um indiscriminado uso de força armada do governo chileno. Estima-se que nesse trágico episódio tenham morrido de 2.500 a 3.600 pessoas, entre as quais trabalhadores chilenos, peruanos e bolivianos, bem como suas famílias, mulheres e crianças. Cf. HOEHN, Marek et al. La masacre de la Escuela Santa María de Iquique: Mirada Histórica desde la Cámara de Diputados. Disponível em: < http://www.bcn.cl/entrevistas/videos_entrevistas/santa_maria.pdf > 
possam reconhecer, nos interstícios dos discursos oficiais, nas fissuras da retórica paramidiática da compensação mercadológica ao esquecimento, as vozes apagadas dos mortos, os sussurros que contam outra história e suas inumeráveis ramificações de possibilidades; e que lembram que "este" presente não é necessariamente "o" que deveria ser.

\subsection{A COMUNA DO CORPO}

Dessa constante tensão entre narrar o passado e conservar o futuro, desse conflito entre o desejo matriarcal de preservar a prole e o desejo da filha de entender as trágicas circunstâncias de suas origens se configura a narrativa de Eltit. A dialética dessa entidade plural, que protagoniza a narrativa, reside no fato de ela estar voltada para esses dois horizontes. E aí talvez esteja um dos pontos mais valiosos da obra. É a filha quem justamente volta-se ao passado, como impulso em direção à perda, enquanto a mãe permanece com os olhos no futuro (instinto pela reminiscência). Movido nessas duas direções, o olhar de ambas despedaça a imagem unívoca da Nação; suas vozes, dissonantes e cacofônicas, assim como seu silêncio, irrompem desconstruindo a linearidade do discurso pátrio. A partir dessa pausa reflexiva, instaurada justamente na resistência dos corpos das protagonistas, é que toda uma constelação histórica é posta em movimento. Em um tempo no qual a medicina moderna parece ter separado corpo e sujeito, Eltit usa, não ocasionalmente, o corpo dessas duas mulheres como alegoria da voz intempestiva de uma força coletiva que resiste à história discursiva de uma modernização totalizadora. Na obra, o corpóreo é a própria escritura, nisso consiste a sua práxis, a narração se dá sempre a partir do corpo da narradora, os pontos referenciais são sempre em relação a sua espacialidade. Mesmo nos momentos em que os corpos da mãe e da filha parecem assumir espaços distintos, eles atuam sempre como extensão do corpo da outra, extensão da própria escritura. Se Eltit dá à filha o papel de narradora, é apenas para que a mãe ancestral possa falar por meio dela. Esse corpo coletivo é o epicentro de onde todas as imagens alegóricas se projetam, e a partir do qual todas as linguagens se fazem possíveis. De sua existência frágil e depauperada, explorada e dissecada pelas juntas médicas que dirigem el hospital, o país, o nación, o patria, é que o indivíduo-coletivo resiste, tanto ao Estado oligárquico, quanto ao Estado-Mercado, ditatorial e pós-ditatorial. Daí que essas duas mulheres, mãe e filha, tenham de ser, desde o seu traumático nascimento, anarquistas. No fundo a narradora sabe que a pátria médica as teme, sabe do poder acumulado de sua experiência, ainda que não possa descrevê-lo enquanto palavra. 
Creo que mi madre, en cualquier minuto, va a hacer estallar el hospital gracias a su condición anarquista. Siento que va a producir un acto inesperado para fundar la sociedad de la resistencia. Pienso que su anarquismo es el poder que tiene mi madre para dar vueltas el mundo si la infamia médica la toca. ${ }^{40}$

Entre consultas médicas, intervenções cirúrgicas de toda a sorte, as mais diversas aplicações medicamentosas, essas duas mulheres sobrevivem, mesmo que seja apenas para lembrar das iniquidades às quais tem se submetido seu corpo. Essas pacientes, armadas apenas de sua "condição anarquista”, resistem a tornarem-se fãs da pátria médica, e sobrevivem, obstinadamente, às incontáveis mortes que se seguem, uma a uma, nos leitos ao seu redor. Ao assumir como sua irrevogável posse esse corpo, ainda que completamente extenuado, essas duas mulheres, representação alegórica de uma força primordial, coletiva, podem sobreviver à tentativa sistemática de aniquilação da história, escrever a crônica mais ardente da postergação, fundar sua comuna, e resistir, como corpo, como escritura e como testemunho.

Solo en la comuna radica la única posibilidad de poner en marcha la primera gran mutual del cuerpo y después, con una esmerada precisión, organizaríamos la gran mutual de la sangre y de esa manera los estudiosos de la pequeña historia van a consignar la existencia de la comuna del cuerpo y de la sangre. ${ }^{41}$

\section{REFERÊNCIAS}

ACHUGAR, Hugo. Planetas sem boca: escritos efêmeros sobre arte, cultura e literatura. Tradução de: Lyslei Nascimento. Belo Horizonte: Editora UFMG, 2006.

AGAMBEN, Giorgio. o que é contemporâneo? e outros ensaios. Tradução de: Vinícius Nicastro Honesko. Chapecó: Argos, 2009.

AVELAR, Idelber. Alegorias da derrota: a ficção pós-ditatorial e o trabalho do luto na América Latina. Tradução de: Saulo Gouveia. Belo Horizonte. Editora UFMG, 2003.

BENJAMIN, Walter. Magia e técnica, arte e política: ensaios sobre literatura e história da cultura. Tradução de: Sérgio Paulo Rouanet 7. Ed. São Paulo: Brasiliense, 1996.

. Origem do drama trágico alemão / Walter Benjamin. Edição e tradução de João Barrento. Belo Horizonte: Autêntica Editora, 2011.

${ }^{40}$ ELTIT, Diamela. Impuesto a la carne. Op. cit., p. 69.

${ }^{41}$ Ibidem, p. 180. 
PERETI, E.; WEINHARDT, M. O TESTEMUNHo DA CARNE: UM PEQUENO TRATAdo SOBRE...

BETHELL, Leslie. (Org.). História da América Latina: da Independência a 1870. Tradução de Maria Clara Cescato. São Paulo: Editora da Universidade de São Paulo; Imprensa Oficial do Estado; Brasília Fundação Alexandre Gusmão, 2002.

BRANDÃO, Luis Alberto. Espaços literários e suas expansões. Disponível em: <http://www. letras.ufmg.br/poslit>. Acesso em: 05/06/2011.

ELTIT, Diamela. Mano de obra. Santiago de Chile: Planeta, 2002.

. Impuesto a la carne. Buenos Aires: Eterna Cadencia Editora, 2010.

FREDRIGO, Fabiana de Souza. Ditadura e resistência no Chile: da democracia desejada à transição possível (1973-1989). Franca: UNESP, 1998b (Série Estudos, n. 03).

GAGNEBIN, Jeanne Marie. História e narração em Walter Benjamin. São Paulo: Perspectiva, 2009.

HOEHN, Marek, et al. La masacre de la Escuela Santa María de Iquique: Mirada Histórica desde la Cámara de Diputados. Disponível em: <http://www.bcn.cl/entrevistas/videos_entrevistas/ santa_maria.pdf>. Acesso em: 19/07/2011.

GRES TOZO, Sergio. Una mirada al movimiento popular desde dos asonadas callejeras (Santiago, 1888-1905). Revista de Estudios Históricos, v. 3, n. 1. ago. 2006. Disponível em: < http://www. estudioshistoricos.uchile.cl/CDA/est_hist_complex/0,1475,SCID\%253D18809\%2526ISID\%253D6 50\%2526PRT\%253D19160,00.html>. Acesso em: 12/07/2011.

KONUT, Karl. SARAVIA, José Morales (Eds.). Literatura chilena hoy: la difícil transición. Madrid: Iberoamericana; Frankfurt/Main: Vervuert, 2002.

NESTROVSKI, Arthur; SELIGMANN-SILVA, Márcio (Orgs.). Catástrofe e representação. São Paulo: Escuta, 2000.

NOVARO, Marcos; PALERMO, Vicente. A ditadura militar argentina 1976-1983: do golpe de estado à restauração democrática. Tradução de Alexandra de Mello e Silva. São Paulo: Editora da Universidade de São Paulo, 2007.

SOMMER, Doris. Ficções de fundação: os romances nacionais da América Latina. Tradução de Gláucia Renate Gonçalves e Eliana Lourenço de Lima Reis. Belo Horizonte: Editora UFMG, 2004.

SUBIRATS, Eduardo. Una última visión del paraíso: ensayos sobre media, vanguardia y la destrucción de culturas en América Latina. México: Fondo de Cultura Económica, 2004.

Submetido em: 26/06/2012

Aceito em: 17/01/2013 